\title{
Modelagem matemática para fumonisinas em milho e perfil cromatográfico de metabólitos produzidos por Fusarium verticillioides
}

\author{
Mathematical modelling for fumonisin production in corn and \\ chromatographic profile of metabolites of Fusarium verticillioides
}

\author{
Luciana Pereira Bernd ${ }^{1 *}$; Adriano Augusto Curioni ${ }^{2}$; Fernando Basso ${ }^{3}$; Eliana Badiale \\ Furlong $;$; Elisabete Yurie Sataque Ono ${ }^{5}$; Antônio Carlos Gerage ${ }^{6}$; Elisa Yoko Hirooka ${ }^{7}$
}

\section{Resumo}

\begin{abstract}
As micotoxinas merecem atenção especial no contexto de saúde pública por desencadearem alterações patológicas em humanos e animais. Dentre estas toxinas, destacam-se as fumonisinas, produzidas principalmente por Fusarium verticillioides, um patógeno primário de milho. O trabalho objetivou desenvolver modelos matemáticos para produção de fumonisinas, bem como avaliar o perfil cromatográfico de metabólitos secundários de Fusarium verticillioides. Grãos de milho submetidos ou não ao tratamento térmico tiveram a umidade ajustada para 15, 20 e 25\%, sendo inoculados ou não com F. verticillioides. Os grãos permaneceram incubados a 20,25 e $30^{\circ} \mathrm{C}$ por 20 dias e, após este período, as fumonisinas foram quantificadas por cromatografia líquida de alta eficiência (CLAE). A temperatura exerceu maior efeito em comparação à umidade $\mathrm{e}$, a maior produção da toxina ocorreu em grãos mantidos a $25 \%$ de umidade sob $20^{\circ} \mathrm{C}$. Os perfis cromatográficos apontaram uma variabilidade nos picos com tempo de retenção diferente de fumonisinas, sugerindo serem compostos oriundos de atividade metabólica, principalmente de $F$. verticillioides. Estes compostos não foram observados nas condições ótimas para produção de fumonisinas e, reduziram com o crescimento de outros gêneros fúngicos. Os modelos matemáticos possibilitaram a predição dos níveis de fumonisinas no $20^{\circ}$ dia subseqüente a partir de dados reais de grãos de milho, sendo submetidos a validações gráfica e matemático-estatística para avaliação de performances. A modelagem matemática poderia auxiliar na compreensão da dinâmica de produção de fumonisinas e conseqüente tomada de decisões que direcionariam o destino da matéria-prima.

Palavras-chave: Controle de qualidade, milho, fumonisinas, modelagem preditiva
\end{abstract}

\begin{abstract}
Mycotoxin requires special attention in public health due to pathological hazard in human and animals. Among these toxins, emphasized are the fumonisin produced mainly by Fusarium verticillioides, which is primary pathogen in corn. This study aimed the development of mathematical models in fumonisin production, as well as to evaluate the chromatography profile of secondary metabolites of Fusarium
\end{abstract}

\footnotetext{
1 Engenheira de Alimentos. Mestre em Ciência de Alimentos. Doutoranda do Programa de Pós-Graduação em Ciência de AlimentosUEL. Depto. de Ciência e Tecnologia de Alimentos/CCA/ UEL. Londrina-Pr. E-mail: lucianabernd@hotmail.com.

2 Acadêmico do Curso de Química/ CCE/ UEL.

3 Engenheiro Agrônomo.

4 Docente do Programa de Pós-Graduação em Engenharia e Ciência de Alimentos - Fundação Universidade Federal do Rio Grande - FURG.

5 Docente do Programa de Mestrado em Biotecnologia -Depto de Bioquímica e Biotecnologia/ CCE/ UEL.

6 Pesquisador do Instituto Agronômico do Paraná - IAPAR, Londrina -PR.

7 Docente do Programa de Pós-Graduação em Ciência de Alimentos - Depto. de Ciência e Tecnologia de Alimentos/ CCA/ UEL.

* Autor para correspondência
} 
verticillioides. Corn (heat-treated or not) was adjusted to 15, 20 and 25\% moisture content, and it was inoculated or not with F. verticillioides. These flasks were incubated at 20,25 and $30^{\circ} \mathrm{C}$ for 20 days, and the fumonisins were quantified by high performance liquid chromatography (HPLC). The temperature affected the fumonisin production in higher extension than moisture content, and the highest fumonisin level was reached at $20^{\circ} \mathrm{C}$ with $25 \%$ moisture content. The chromatogram profiles showed many peaks with retention time which differed of fumonisin, suggesting diversity in compounds arisen from metabolic pathway, which were also from F. verticillioides. These metabolites were not observed in optimized condition for fumonisin production, showing decreased trend when other fungal growth was increased. The mathematical models predicted the fumonisin level trend at the 20th day's performance in a real data contamination evaluated in corn, which were submitted to graphical and mathematical/ statistical validations. The mathematical modelling can be an important tool in understanding the dynamic of fumonisin production and further decision of adequate raw material destination.

Key words: Quality control, corn, fumonisins, predictive modelling

\section{Introdução}

A agropecuária constitui base da economia brasileira, garantindo o fornecimento contínuo de insumos de origem vegetal e animal, sendo o cenário mundial atual favorável à consolidação do país como grande exportador. Em 2006, a produção total de cereais, leguminosas e oleaginosas do Brasil atingiu 116,6 milhões de toneladas; sendo que para o ano de 2007, o IBGE estima uma produção superior em 9,7\% ao ano anterior. O Estado do Paraná mantém-se líder na produção de milho, trigo e feijão e a condição de segundo produtor de soja. O Estado, que em 2006 produziu 11,1 milhões de toneladas de milho (safras de verão e inverno), apresenta uma previsão de colheita superior na ordem de $11,2 \%$ (INSTITUTO BRASILEIRO DE GEOGRAFIA E ESTATÍSTICA - IBGE, 2007).

O milho é uma importante fonte nutricional e componente constante na alimentação humana, além de representar 60 a $70 \%$ da composição de rações empregadas na suinocultura e avicultura. Outrossim, sua qualidade nutricional confere característica de substrato ideal, que aliado ao clima tropicalsubtropical predominante no Brasil (temperatura e umidade), favorece o crescimento fúngico, sendo constante motivo de preocupação em relação ao perigo de deterioração de grãos e da produção de micotoxinas (RODRIGUEZ-AMAYA, 2000).

Alimentos destinados ao consumo humano sofrem contaminações das mais variadas origens desde o plantio, colheita, armazenamento da matéria-prima, processamento e embalagem à comercialização do produto final (LAZZARI; LAZZARI, 2000). No caso de grãos, o principal perigo relacionado à infestação microbiana refere-se ao crescimento fúngico, uma vez que estes produzem metabólitos secundários, as micotoxinas, capazes de causar alterações patológicas resultantes de anormalidades fisiológicas em humanos e animais (MALLMANN, 1998).

Fusarium verticillioides Niremberg (= Fusarium moniliforme Sheldon) destaca-se entre os fungos envolvidos na qualidade pós-colheita de milho (BULLERMAN, 1996), cujo metabólito secundário tóxico principal produzido pertence ao grupo de fumonisinas, classificadas como carcinógenos do grupo $2 \mathrm{~B}$, isto é, possivelmente carcinogênico a humanos pelo "International Agency for Research on Câncer" (WORLD HEALTH ORGANIZATION..., 2002).

A ocorrência de Fusarium verticillioides em milho e a possibilidade de produção de fumonisinas (YAMAGUCHI; HIROOKA; SHIBATA, 1992; HIROOKA; YAMAGUCHI; AOYAMA, 1996; MALLMANN; SANTURIO; DILKIN 1997; ORSI; CORRÊA; POZZI, 2000), justificam a necessidade de estudo direcionado ao ponto crítico de controle na produção destas toxinas.

Em face disto, o trabalho visa contribuir com a minimização de contaminação de milho por meio do estudo da dinâmica da produção de fumonisina, bem como propor modelo matemático preditivo para este metabólito. 


\section{Material e Métodos}

\section{Matéria-prima}

A matéria-prima utilizada no desenvolvimento do trabalho foi o milho do híbrido simples Tork (textura dura e cor laranja), pertencente à safra março/2005 da empresa Syngenta, regiões dos municípios de Londrina e Santa Helena - PR, e fornecido pelo Instituto Agronômico do Paraná (IAPAR). O lote foi homogeneizado em misturador rotativo, em forma de $\mathrm{V}$, dividido em sacos plásticos de $1 \mathrm{Kg}$ e mantido a $5^{\circ} \mathrm{C}$ até o uso.

Grãos de milho da região Norte do Estado do Paraná da safra de 2004 foram fornecidos por uma cooperativa da região, amostrando-se $500 \mathrm{~g}$ de milho imediatamente após a colheita (no campo), nos caminhões antes da descarga na moega e na saída da moega (antes da secagem); procedendo-se à quantificação de fumonisinas após a amostragem. Estas amostras foram parte integrante de um estudo que objetivou determinar os Pontos de Controle relacionados à contaminação com fumonisinas na cadeia produtiva do milho (Projeto FINEP - Cadeia Produtiva de Milho, 2004) e foram utilizados seus dados de contaminação de fumonisinas para aplicação nos modelos matemáticos desenvolvidos.

\section{Cultura fúngica}

Fusarium verticillioides da cepa $103 \mathrm{~F}$, isolada de ração envolvida em intoxicação animal, foi utilizada no estudo. O inóculo foi preparado em água destilada contendo $0,1 \%$ de Tween 80 , empregando cultivo ativado em ágar batata dextrose. A seguir procedeuse à contagem em câmara de Newbauer $\left(2,33 \times 10^{7}\right.$ conídios/mL de suspensão) para inocular 4,64 x 104 esporos/g de milho.

\section{Procedimento experimental}

Alíquotas de $500 \mathrm{~g}$ de milho submetidas a tratamento térmico à $121^{\circ} \mathrm{C}$ por $15 \mathrm{~min}$ e, iguais quantidades não submetidas a este processo, foram ajustadas à umidade de 15, 20 e 25\% adicionando-se água destilada estéril, utilizando a equação (1). Os grãos, contendo $0,15 \%$ de solo estéril como adsorvente, foram inoculados com a suspensão de F. verticillioides (4,67 x $10^{4}$ esporos/g de milho) e incubados por 20 dias em estufas tipo BOD, a 20, 25 e $30^{\circ} \mathrm{C}$. O controle negativo consistiu de grãos de milho sem inóculo do fungo e submetidos às mesmas condições. Os erlenmeyers foram manualmente homogeneizados, sendo o procedimento repetido a cada 7 dias de incubação, para melhorar a distribuição fúngica.

$$
\begin{gathered}
\mathrm{mL} \text { água estéril }=\{[(100-\text { umidade inicial }) / \\
(100-\text { umidade final })]-1\} \times \text { x peso amostra }(g)
\end{gathered}
$$

Procedeu-se, desta maneira, a um planejamento fatorial completo com duas variáveis em três níveis (umidade e temperatura) e uma variável em dois níveis (inóculo de F. verticillioides), por 20 dias de incubação. Sendo assim, o planejamento foi composto por 22 experimentos aleatorizados, sendo 3 repetições no ponto central, para testar a hipótese de que a variabilidade no ponto central não difere da variabilidade na região experimental.

Os grãos foram avaliados quanto à concentração de fumonisinas pré (tempo zero; $\mathrm{t}_{0}$ ) e pós-período de ensaio (20 dias; $\mathrm{t}_{20}$ ), sendo que os dados necessários para a elaboração de modelos matemáticos foram obtidos por subtração dos valores destes dois períodos de análise, para milho submetido ao tratamento térmico $\left(121^{\circ} \mathrm{C} / 15 \mathrm{~min}\right)$.

Posteriormente, os dados reais de umidade e temperatura, provenientes da safra 2004 (FINANCIADORA DE PRODUTOS E PROJETOS - FINEP, 2004), foram utilizados nos modelos matemáticos desenvolvidos. Desta maneira, as respostas preditivas, para um período de 20 dias de concentração de fumonisinas $\mathrm{B}_{1}, \mathrm{~B}_{2}$ e $\mathrm{B}_{\text {total }} \mathrm{em}$ grãos de milho, foram confrontadas com as das análises realizadas logo após a amostragem por pesquisadores envolvidos no Projeto FINEP. 


\section{Determinação de fumonisinas}

As fumonisinas foram quantificadas por cromatografia líquida de alta eficiência - CLAE, segundo Shephard et al. (1990), modificado por Ueno et al. (1993). As fumonisinas foram extraídas com metanol:água $(3: 1, \mathrm{v} / \mathrm{v})$, purificadas empregando-se mini-colunas de troca iônica Sep-Pak accell plus QMA (Waters Co., Ltda), derivatizadas com oftaldialdeído-OPA e o eluato injetado em sistema CLAE isocrático de fase reversa da Shimadzu, equipado com coluna $\mathrm{C}_{18}(80 \mathrm{x} 15 \mathrm{~mm})$ e detector de fluorescência. Os comprimentos de onda de excitação e emissão foram $335 \mathrm{~nm}$ e $450 \mathrm{~nm}$, respectivamente. A fase móvel consistiu de metanol: fosfato de sódio $0,1 \mathrm{M}$ (80:20, v/v) pH 3,3 (ácido ortofosfórico), ajustado para o fluxo de $1,0 \mathrm{~mL} / \mathrm{min}$. Os limites de detecção para $\mathrm{FB}_{1}$ e $\mathrm{FB}_{2}$ foram 50ng/g e 80ng/g, respectivamente, os quais foram determinados em trabalhos prévios.

Os perfis cromatográficos do substrato milho, tanto pré quanto pós tratamento térmico, foram analisados para identificação e quantificação de fumonisinas, assim como para detecção dos demais compostos produzidos por gêneros fúngicos, durante o planejamento experimental em estudo.

\section{Métodos matemáticos e estatísticos}

A distribuição normal dos dados, por meio do Teste de Shapiro-Wilk's W. e, a homogeneidade das variâncias, mediante aplicação do teste de Levene, foram utilizadas para averiguar a aplicabilidade da análise de variância (ANOVA).

Os coeficientes dos modelos e suas significâncias associadas aos fatores foram determinados mediante ajuste dos modelos ao conjunto de dados, usando-se análise de variância. Para verificar que não houve falta de ajuste dos dados ao modelo construído, testouse a média quadrática devida ao erro puro, utilizando o programa "Software Statistica", versão 5.1.

As variáveis estudadas no milho, consistindo de umidade $\left(\mathrm{X}_{1}\right)$, inóculo $\left(\mathrm{X}_{2}\right)$ e temperatura $\left(\mathrm{X}_{3}\right)$ foram aplicadas no modelo sob a forma codificada, conforme equação (2).
(2)

Variável codificada $=($ Variável descodificada $)-($ Ponto central $)$ Metade da faixa

Para avaliação da dinâmica da produção de fumonisinas foram utilizadas as superfícies tridimensionais dos modelos construídos em função das variáveis investigadas.

\section{Validação dos modelos matemáticos}

\section{Validação matemática/estatística}

Para avaliar a performance dos modelos preditivos de produção de fumonisinas foram calculados o coeficiente de determinação $\left(\mathrm{R}^{2}\right)$, erro médio quadrático (EMQ) e fator de viés.

\section{Validação gráfica}

A confiabilidade geral dos modelos também foi analisada pela visualização de propriedades gerais dos modelos matemáticos desenvolvidos, procedendo à plotagem das respostas observadas em função das preditas, bem como através do gráfico da distribuição normal de resíduos.

\section{Resultados e Discussão}

O lote do híbrido Tork safra março/2005 (Tabela $\left.1 ; \mathrm{t}_{0}\right)$ apresentou níveis de fumonisinas $\left(\mathrm{FB}_{1}=3,78 \pm\right.$ $1,25 \mu \mathrm{g} / \mathrm{g} ; \mathrm{FB}_{2}=0,91 \pm 0,34 \mu \mathrm{g} / \mathrm{g}$ ) dentro do limite máximo de $5,10,50$ e $50 \mu \mathrm{g} / \mathrm{g}$ recomendado para eqüino, suíno, bovino e ave, respectivamente, pelo "Mycotoxin Committee of the American Association of Veterinary Laboratory Diagnosticians" (MUNKVOLD; DESJARDINS, 1997). Não obstante, aquém do estabelecido pelo órgão legislador "United States Food and Drug Administration", considerando os limites de 2,3 e $4 \mu \mathrm{g} / \mathrm{g}$ recomendados para farelo de milho, milho para pipoca e milho para produção de massas, respectivamente. 
O milho utilizado (Tabela $1 ; \mathrm{t}_{0}$ ) apresentou perfil de contaminação natural semelhante aos estudos prévios realizados em 37 amostras de milho recémcolhido do Norte do Paraná (ONO et al., 1999), mostrando a dificuldade de obtenção de milho isento de fumonisinas. As fumonisinas $\mathrm{B}_{1}$ e $\mathrm{B}_{2}$ foram detectadas em todas as amostras, com níveis variando de 0,37 a $13,46 \mu \mathrm{g} / \mathrm{g}$ (média de $4,56 \pm 2,97 \mu \mathrm{g} / \mathrm{g}$ ) e de 0,20 a $6,92 \mu \mathrm{g} / \mathrm{g}$ (média de 2,20 $\pm 1,45 \mu \mathrm{g} / \mathrm{g}$ ), respectivamente (ONO et al., 1999).

Tabela 1. Perfil da contaminação de fumonisinas $\left(\mathrm{FB}_{1}\right.$ e $\left.\mathrm{FB}_{2}\right)$ em milho safra março/2005 utilizado no ensaio (tempo inicial $-\mathrm{t}_{0}$ ) e resultados do planejamento experimental (após 20 dias de estocagem $-\mathrm{t}_{20}$ )

\begin{tabular}{|c|c|c|c|c|}
\hline \multicolumn{5}{|c|}{$\mathrm{t}_{0}$} \\
\hline \multicolumn{3}{|c|}{ Contaminação ( $\mu \mathrm{g} / \mathrm{g})$} & $\begin{array}{c}\mathrm{FB}_{1} \\
3,78 \pm 1,25\end{array}$ & $\begin{array}{c}\mathrm{FB}_{2} \\
0,91 \pm 0,34\end{array}$ \\
\hline \multicolumn{5}{|c|}{$t_{20}$} \\
\hline $\mathrm{U}$ & I & $\mathrm{T}$ & $\mathrm{FB}_{1}(\mu \mathrm{g} / \mathrm{g})$ & $\mathrm{FB}_{2}(\mu \mathrm{g} / \mathrm{g})$ \\
\hline-1 & +1 & -1 & 1,76 & 0,97 \\
\hline 0 & +1 & -1 & 28,46 & 6,66 \\
\hline+1 & +1 & -1 & 20,17 & 9,05 \\
\hline-1 & -1 & -1 & 1,29 & 0,25 \\
\hline 0 & -1 & -1 & 4,77 & 2,85 \\
\hline+1 & -1 & -1 & 15,65 & 5,33 \\
\hline-1 & +1 & 0 & 5,87 & 0,76 \\
\hline 0 & +1 & 0 & 2,31 & 0,89 \\
\hline 0 & +1 & 0 & 10,25 & 2,76 \\
\hline 0 & +1 & 0 & 5,25 & 2,13 \\
\hline+1 & +1 & 0 & 8,78 & 2,28 \\
\hline-1 & -1 & 0 & 5,33 & 2,10 \\
\hline 0 & -1 & 0 & 1,19 & 1,11 \\
\hline 0 & -1 & 0 & 2,58 & 0,98 \\
\hline 0 & -1 & 0 & 9,33 & 2,03 \\
\hline+1 & -1 & 0 & 8,44 & 2,46 \\
\hline-1 & +1 & +1 & 3,34 & 1,46 \\
\hline 0 & +1 & +1 & 2,95 & 1,21 \\
\hline+1 & +1 & +1 & 4,82 & 1,38 \\
\hline-1 & -1 & +1 & 1,91 & 0,28 \\
\hline 0 & -1 & +1 & 2,80 & 2,05 \\
\hline+1 & -1 & +1 & 8,21 & 2,67 \\
\hline
\end{tabular}

*I (inóculo de F. verticillioides): $(-1)=$ sem inoculação de esporos de F. verticillioides; $(+1)$ com inoculação de esporos de F. verticillioides; U (Umidade): (-1) 15\%; (0) 20\%; (+1) 25\%; T (Temperatura): (-1) $20^{\circ} \mathrm{C}$; (0) $25^{\circ} \mathrm{C}$; (+1) $30^{\circ} \mathrm{C}$.

Os dados obtidos para a contaminação de fumonisinas pelo planejamento fatorial realizado estão expressos na Tabela $1 ; \mathrm{t}_{20}$. Para o desenvolvimento dos modelos matemáticos e análise dos efeitos de cada variável sobre as respostas obtidas procedeuse a um planejamento fatorial completo, submetendo os grãos ao tratamento térmico $\left(121^{\circ} \mathrm{C} / 15 \mathrm{~min}\right)$, sendo que a análise de normalidade, mediante aplicação do teste de Shapiro-Wilk's W., demonstrou que os dados não seguiram uma distribuição normal; no entanto, a análise pelo teste de Levene demonstrou que as variâncias das respostas obtidas apresentaram homogeneidade. Portanto, a análise de variância (ANOVA) pôde ser aplicada para avaliação individual de cada parâmetro.

Os coeficientes dos modelos matemáticos desenvolvidos para fumonisinas $\mathrm{B}_{1}, \mathrm{~B}_{2} \mathrm{e}$ fumonisina total, baseados na obtenção do maior valor do coeficiente de determinação $\left(\mathrm{R}^{2}\right)$, menor erro médio quadrático (EMQ) e falta de ajuste não significativa ( $>>0,05)$, estão expressos na Tabela 2. 
Tabela 2. Modelos matemáticos para a produção de $\mathrm{FB}_{1}$ e $\mathrm{FB}_{2}$ e fumonisina total

\begin{tabular}{|c|c|c|}
\hline & \multicolumn{2}{|c|}{$\overline{\mathbf{F B}_{1}}$} \\
\hline Constante & $3,233 \pm 1,223$ & $*$ \\
\hline \multicolumn{3}{|c|}{ Termos lineares $(\mathrm{X})$} \\
\hline $\mathrm{X}_{1}$ & $2,762 \pm 1,116$ & $*$ \\
\hline $\mathrm{X}_{2}$ & $1,320 \pm 1,402$ & --- \\
\hline $\mathrm{X}_{3}$ & $-5,930 \pm 1,933$ & $* *$ \\
\hline \multicolumn{3}{|c|}{ Termos quadráticos $\left(\mathrm{X}^{2}\right)$} \\
\hline $\mathrm{X}_{3}$ & $2,896 \pm 1,655$ & --- \\
\hline \multicolumn{3}{|c|}{ Produto de termos $(\mathrm{X} . \mathrm{X})$} \\
\hline$X_{1}^{2} \cdot X_{2}$ & $-3,027 \pm 1,718$ & --- \\
\hline $\mathrm{X}_{1} \cdot \mathrm{X}_{3}$ & $-3,766 \pm 1,367$ & * \\
\hline $\mathrm{X}_{1}^{2} \cdot \mathrm{X}_{3}$ & $2,868 \pm 2,638$ & --- \\
\hline$X_{2} \cdot X_{3}$ & $-2,684 \pm 1,116$ & * \\
\hline \multirow[t]{2}{*}{$X_{2} \cdot X_{3}^{2}$} & $2,637 \pm 1,718$ & --- \\
\hline & \multicolumn{2}{|c|}{$\mathbf{F B}_{2}$} \\
\hline Constante & $1,240 \pm 0,257$ & $* * *$ \\
\hline \multicolumn{3}{|c|}{ Termos lineares $(\mathrm{X})$} \\
\hline $\mathrm{X}_{1}$ & $0,470 \pm 0,406$ & --- \\
\hline $\mathrm{X}_{2}$ & $0,261 \pm 0,294$ & --- \\
\hline$X_{3}$ & $-1,356 \pm 0,234$ & $* * *$ \\
\hline \multicolumn{3}{|c|}{ Termos quadráticos $\left(\mathrm{X}^{2}\right)$} \\
\hline $\mathrm{X}_{3}$ & $0,805 \pm 0,348$ & * \\
\hline \multicolumn{3}{|c|}{ Produto de termos $(\mathrm{X} . \mathrm{X})$} \\
\hline $\mathrm{X}_{1} \cdot \mathrm{X}_{2}$ & $0,395 \pm 0,234$ & --- \\
\hline $\mathrm{X}_{1}^{2} \cdot \mathrm{X}_{2}$ & $-0,618 \pm 0,361$ & --- \\
\hline$X_{1} \cdot X_{3}$ & $-1,298 \pm 0,287$ & $* * *$ \\
\hline $\mathrm{X}_{1} \cdot \mathrm{X}_{3}^{2}$ & $1,001 \pm 0,497$ & --- \\
\hline$X_{2} \cdot X_{3}$ & $-0,781 \pm 0,234$ & $* *$ \\
\hline \multirow[t]{2}{*}{$\mathrm{X}_{2} \cdot \mathrm{X}_{3}^{2}$} & $0,504 \pm 0,361$ & --- \\
\hline & \multicolumn{2}{|c|}{$\mathbf{F B}_{\text {total }}$} \\
\hline Constante & $4,473 \pm 1,435$ & $* *$ \\
\hline \multicolumn{3}{|c|}{ Termos lineares $(\mathrm{X})$} \\
\hline $\mathrm{X}_{1}$ & $3,900 \pm 1,310$ & * \\
\hline $\mathrm{X}_{2}$ & $1,581 \pm 1,647$ & --- \\
\hline $\mathrm{X}_{3}$ & $-5,374 \pm 1,310$ & ** \\
\hline \multicolumn{3}{|c|}{ Termos quadráticos $\left(\mathrm{X}^{2}\right)$} \\
\hline $\mathrm{X}_{3}$ & $3,701 \pm 1,944$ & --- \\
\hline \multicolumn{3}{|c|}{ Produto de termos (X. X) } \\
\hline $\mathrm{X}_{1}^{2} \cdot \mathrm{X}_{2}$ & $-3,645 \pm 2,017$ & --- \\
\hline$X_{1} \cdot X_{3}$ & $-5,065 \pm 1,605$ & $* *$ \\
\hline $\mathrm{X}_{2} \cdot \mathrm{X}_{3}$ & $-3,465 \pm 1,310$ & $*$ \\
\hline$X_{2} \cdot X_{3}^{2}$ & $3,141 \pm 2,017$ & --- \\
\hline
\end{tabular}

— não significativo; ${ }^{*} \mathrm{p}<0,05 ; * * \mathrm{p}<0,01 ; * * \mathrm{p}<0,001 . \quad \mathrm{X}_{1}=$ umidade, $\mathrm{X}_{2}=$ inóculo, $\mathrm{X}_{3}=$ temperatura.

A temperatura exerceu efeito mais significativo na produção de fumonisinas se comparado com a umidade, conforme significâncias dos coeficientes dos modelos desenvolvidos (Tabela 2). Considerando que o metabolismo secundário se inicia na fase estacionária de crescimento microbiano, i.e., a contagem microbiana tende a manter-se constante, fatores integrantes diretos como substrato na reação bioquímica (ex: água) não teriam efeito substancial na biossíntese da toxina. Por outro lado, fatores físicos, como condições climáticas, transporte e processos empregados na secagem poderiam causar uma mudança drástica nas condições de grãos expostos no campo (choque térmico, interrupção no fornecimento de nutrientes pela colheita), bloqueando os mecanismos naturais de defesa e processos 
fisiológicos da planta, que desencadeiam a indução de enzimas envolvidas no metabolismo secundário (KADOZAWA et al., 2006).

Houve uma tendência ao aumento da produção de fumonisnas com a redução da temperatura $\left(20^{\circ}\right.$ C) e aumento da umidade (25\%) em milho inoculado com F. verticillioides (Figura 1). O resultado foi similar ao relatado por Scott (1993), em que ocorreu maior produção de fumonisinas a $20^{\circ} \mathrm{C}$ e, corrobora com pesquisas que demonstraram aumento nos níveis de fumonisinas em regiões sub-tropicais (HIROOKA; YAMAGUCHI; AOYAMA, 1996;

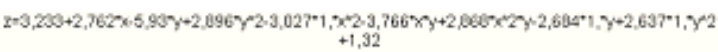

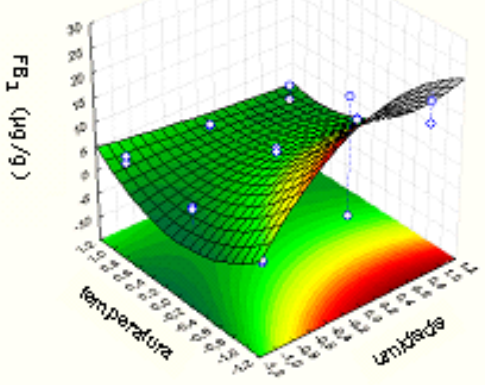

(a)
SCUDAMORE; PATEL, 2000). Esta temperatura também foi a ideal para produção destas toxinas utilizando substrato arroz (HINOJO et al., 2006). Dilkin et al. (2002) obtiveram as maiores concentrações de fumonisinas em $20 \%$ de umidade a $25^{\circ} \mathrm{C}$. No entanto, a contradição com os resultados deste trabalho pode ser devido à diferença na cepa de F. verticillioides utilizada, uma vez que esses autores empregaram as cepas 113F, LAMIC 2999/96 e NRRL 13616, enquanto que foi empregada a cepa $103 \mathrm{~F}$ nesta modelagem. Salienta-se que a cepa pertence à cultura mantida em nosso laboratório desde 1991, portanto com a característica genética estabilizada.

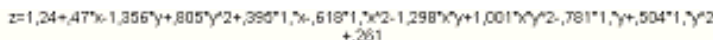

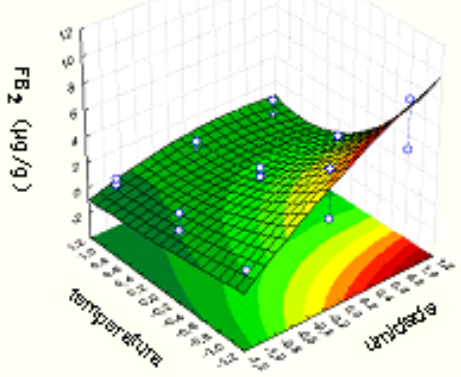

(b)

Figura 1. Superfícies de resposta da produção de fumonisina $B_{1}(a)$ e $B_{2}(b)$ versus umidade e temperatura, mantido a presença de inóculo.

\section{Validação matemática/estatística dos modelos matemáticos}

Os resultados das análises matemáticas/ estatísticas usadas para avaliar a performance de modelos matemáticos para a produção de fumonisinas $\mathrm{B}_{1}$, $\mathrm{B}_{2}$ e total $\left(\mathrm{FB}_{1}+\mathrm{FB}_{2}\right)$ nos grãos de milho estão apresentados na Tabela 3. A variabilidade dos dados em torno do ponto central não diferiu da variabilidade na região experimental nos três modelos, uma vez que a falta de ajuste não foi significativa $(\mathrm{p}>0,05)$.
$\mathrm{O}$ modelo desenvolvido para a produção de $\mathrm{FB}_{2}$ apresentou maior capacidade para predição (mais exato), explicando $82 \%$ dos dados experimentais ( $\mathrm{R}^{2}$ $=0,82)$, aliado a menor média residual $(0,661)$ e um fator de viés de 0,94 , indicando ser um modelo que super-estima os dados preditos. Os modelos para a produção de $\mathrm{FB}_{1}$ e $\mathrm{FB}_{\text {total}}$, apesar de também não apresentarem falta de ajuste significativo $(\mathrm{p}>0,05)$, explicaram 61,8 e 67,9\% dos dados, apresentando o primeiro modelo característica de super-estimação (fator de viés= 0,75 ), e o segundo, de sub-estimação (fator de viés=1,02). 
Bernd, L. P. et al.

Tabela 3. Índices de, validação para a performance dos modelos matemáticos

\begin{tabular}{ccccc}
\hline $\mathrm{Y}$ & EMQ* $^{*}$ & $\mathrm{FA}^{* *}$ ("p") & $\mathrm{R}^{2}(\%)$ & Fator de viés \\
\hline $\mathrm{FB}_{1}$ & 14,957 & 0,1729 & 61,8 & 0,75 \\
$\mathrm{FB}_{2}$ & 0,661 & 0,4866 & 82,0 & 0,94 \\
$\mathrm{FB}_{\text {total }}$ & 20,618 & 0,2238 & 67,9 & 1,02 \\
\hline
\end{tabular}

*EMQ = erro médio quadrático; $*$ FA = falta de ajuste.

Validação gráfica dos modelos matemáticos

As plotagens das respostas observadas na produção de $\mathrm{FB}_{1}, \mathrm{FB}_{2}$ e $\mathrm{FB}_{\text {total }}$, em função das preditas pelos modelos e os gráficos da distribuição normal dos resíduos estão mostrados na Figura 2. Os dados apresentaram um ajuste adequado em relação à distribuição normal dos resíduos nos três modelos preditivos, estando estes próximos à linha de equivalência. $\mathrm{O}$ modelo para produção de $\mathrm{FB}_{2}$ apresentou melhor predição (Figura 2b), devido a maior proximidade à linha de tendência pela plotagem dos dados experimentais versus preditos, se comparados aos modelos de $\mathrm{FB}_{1}$ e $\mathrm{FB}_{\text {total }}$ (Figura 2a e 2c).

\section{Aplicação de dados reais aos modelos matemáticos}

Mediante utilização de modelos matemáticos desenvolvidos, é possível obter a tendência atingida no $20^{\circ}$ dia (tempo de manutenção fixado em $t_{20}$ ), quanto aos níveis de fumonisinas (Tabela 4). Salientase que o modelo é válido, desde que as condições estabelecidas no $t_{0}$ permaneçam constantes, i.e., mantidas inalteradas até o $t_{20} e$, em grãos de milho mantidos dentro das faixas de umidade e temperatura utilizadas no desenvolvimento da equação $\left(15 \% \leq\right.$ umidade $\leq 25 \% ; 20^{\circ} \mathrm{C} \leq$ temperatura $\left.\leq 30^{\circ} \mathrm{C}\right)$.

Conhecendo-se as restrições, para simular o perfil de fumonisinas em $t_{20}$, os modelos desenvolvidos (Tabela 2) foram aplicados empregando dados reais obtidos na análise de milho safra 2004, pertencentes ao Projeto FINEP - Cadeia Produtiva de Milho (Tabela 4). Para efetivar a equação, codificaram-se as variáveis originais de umidade, temperatura e inóculo de F. verticillioides mediante aplicação da fórmula (1). A seguir, os valores de variáveis codificados obtidos foram introduzidos nos modelos matemáticos desenvolvidos, para a predição no tempo $\mathrm{t}_{20}$ dos níveis de $\mathrm{FB}_{1}, \mathrm{FB}_{2}$ e $\mathrm{F}_{\text {total }}$ (Tabela 4).

A seleção de 17 amostras de milho para o estudo (dados reais, pertencentes ao Projeto FINEP) baseou-se nas condições propostas na modelagem para variáveis originais. Portanto, apresentavam umidade entre 16,5 a $22,6 \%$, temperatura entre 25 a $30^{\circ} \mathrm{C}$ e a contagem de Fusarium spp. entre $1,2 \times 10^{4}$ a 9,0x $10^{4} \mathrm{UFC} / \mathrm{g}$ (considerando que o inóculo de $F$. verticillioides $103 \mathrm{~F}$ aplicado no milho tratado foi de $10^{4} \mathrm{UFC} / \mathrm{g}$ ), sendo todas pertencentes à amostragem realizada na entrada da moega. A temperatura mínima considerada no estudo foi de $25^{\circ} \mathrm{C}$ (Tabela 4), tendo em vista que nos dados reais não constavam amostras com temperaturas inferiores a este valor.

Conforme Tabela 4, os níveis de fumonisinas obtidos, tanto nos dados reais $\left(\mathrm{t}_{0}\right)$ quanto nas respostas preditas pelos modelos matemáticos $\left(\mathrm{t}_{20}\right)$, variaram de 0,07 a $6,05 \mu \mathrm{g} / \mathrm{g}$, sendo que a quantificação de fumonisina total nos dados reais foi de 0,07 a 3,55 $\mu \mathrm{g} / \mathrm{g}\left(\mathrm{t}_{0}\right)$ e atingiu níveis preditos de 2,46 a $6,05 \mu \mathrm{g} / \mathrm{g}$ $\left(t_{20}\right)$. Considerando que o limite recomendado para eqüídeo (um dos animais mais sensíveis) seja de 5 $\mu \mathrm{g} / \mathrm{g}$, segundo o "Mycotoxin Committee of the American Association of Veterinary Laboratory Diagnosticians", a concentração de fumonisinas situou-se em valores inferiores em todas as amostras no $t_{0}$, mas no $t_{20}, 3$ amostras que continham entre 5,12 a $6,05 \mu \mathrm{g} / \mathrm{g}$ de fumonisinas ultrapassaram o valor. 


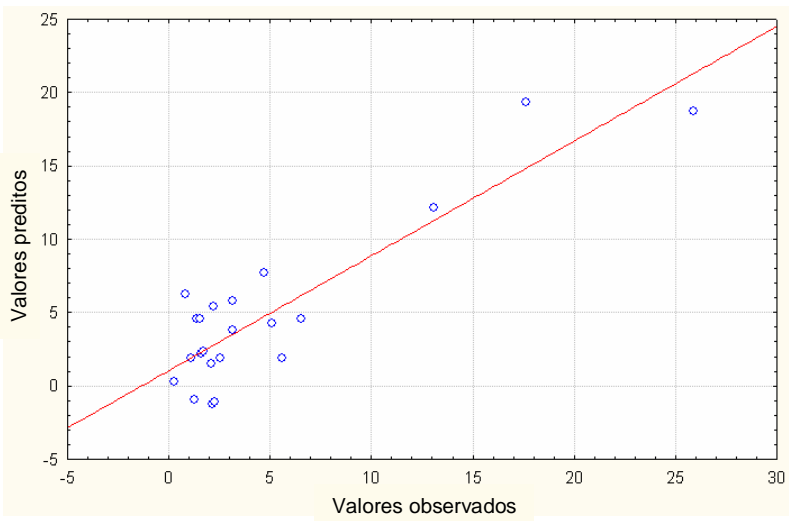

(a)

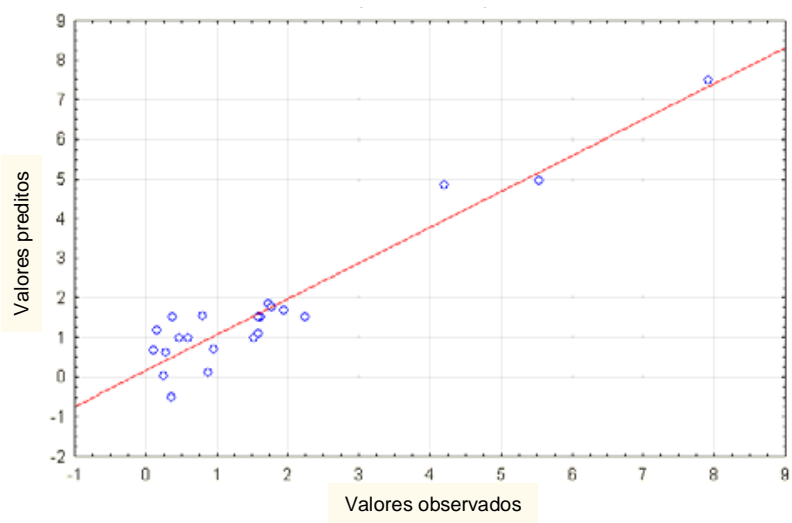

(b)

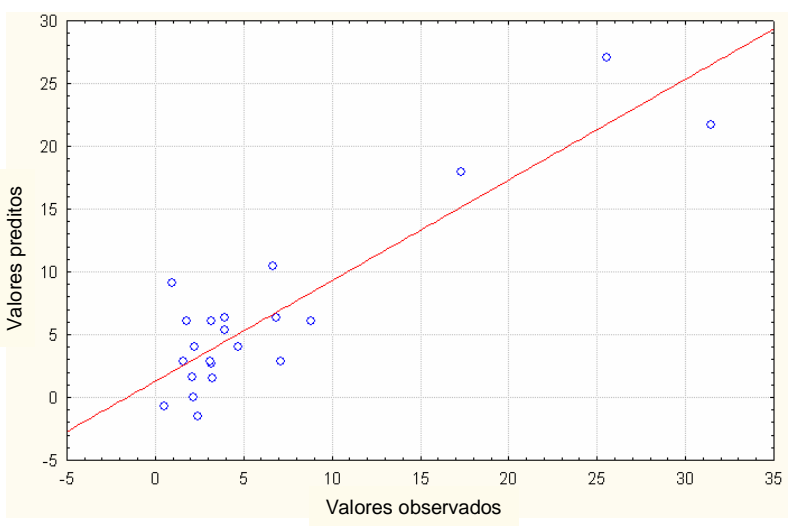

(c)

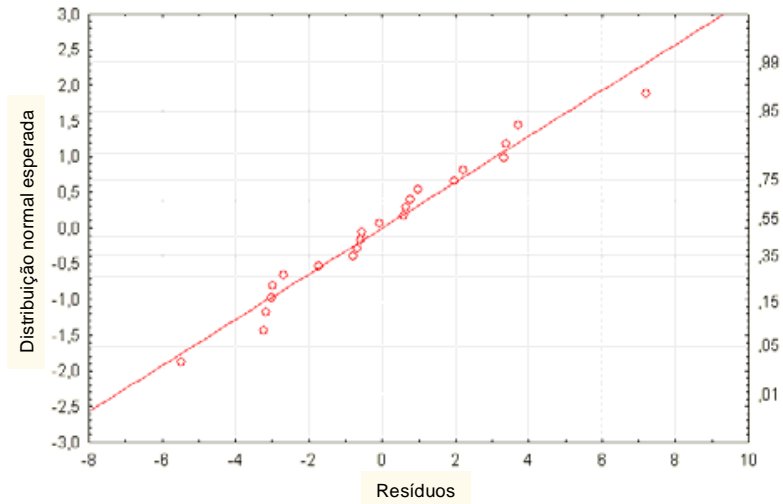

(d)

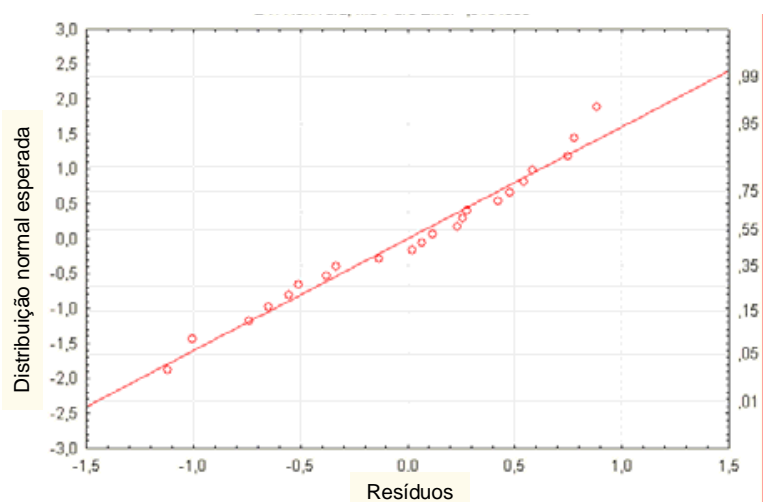

(e)

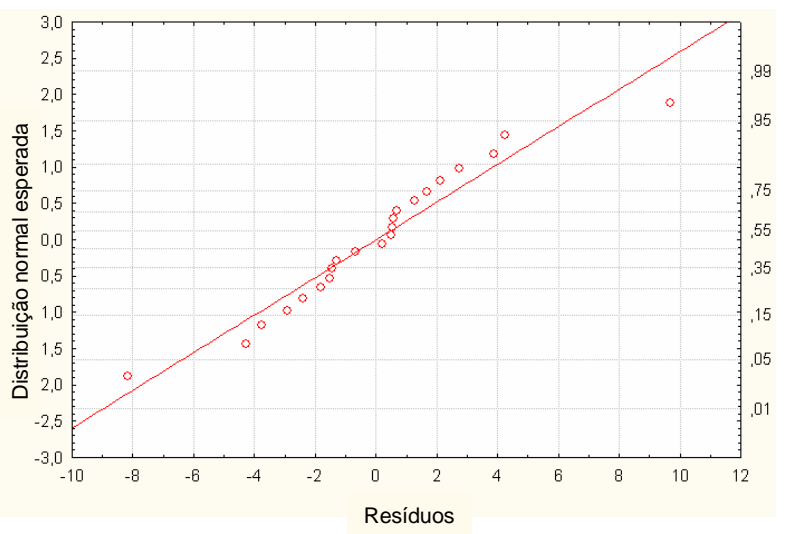

(f)

Figura 2. Respostas observadas de produção de $\mathrm{FB}_{1}(\mathrm{a}), \mathrm{FB}_{2}$ (b) e $\mathrm{FB}_{\text {total }}$ (c) em função das preditas pelo modelo; distribuição normal dos resíduos do modelo de produção de $\mathrm{FB}_{1}(\mathrm{~d}), \mathrm{FB}_{2}(\mathrm{e})$ e $\mathrm{FB}_{\text {total }}(\mathrm{f})$. 
Tabela 4. Aplicação de dados reais (Projeto FINEP - Cadeia Produtiva de Milho) aos modelos matemáticos desenvolvidos para $\mathrm{FB}_{1}, \mathrm{FB}_{2}$ e $\mathrm{FB}_{\text {total }}$

\begin{tabular}{|c|c|c|c|c|c|c|c|c|c|c|c|}
\hline \multicolumn{3}{|c|}{ Variáveis originais } & \multicolumn{3}{|c|}{ Variáveis codificadas } & \multicolumn{3}{|c|}{ Respostas reais $\left(\mathrm{t}_{0}\right)$} & \multicolumn{3}{|c|}{ Respostas preditas $\left(t_{20}\right)$} \\
\hline $\begin{array}{l}U^{*} \\
(\%)\end{array}$ & $\begin{array}{c}\mathrm{T}^{*} \\
\left({ }^{\circ} \mathrm{C}\right)\end{array}$ & $\begin{array}{c}\mathrm{I}^{*} \\
(\mathrm{UFC} / \mathrm{g})\end{array}$ & $\mathrm{U}^{*}$ & $\mathrm{~T}^{*}$ & $I^{*}$ & $\begin{array}{c}\mathrm{FB}_{1} \\
(\mu \mathrm{g} / \mathrm{g})\end{array}$ & $\begin{array}{c}\mathrm{FB}_{2} \\
(\mu \mathrm{g} / \mathrm{g})\end{array}$ & $\begin{array}{l}\mathrm{FB}_{\text {total }} \\
(\mu \mathrm{g} / \mathrm{g})\end{array}$ & $\begin{array}{c}\mathrm{FB}_{1} \\
(\mu \mathrm{g} / \mathrm{g})\end{array}$ & $\begin{array}{c}\mathrm{FB}_{2} \\
(\mu \mathrm{g} / \mathrm{g})\end{array}$ & $\begin{array}{l}\mathrm{FB}_{\text {total }} \\
(\mu \mathrm{g} / \mathrm{g})\end{array}$ \\
\hline 19,1 & 30,0 & $1,6 \times 10^{4}$ & $-0,18$ & 1 & 1 & 0,13 & $\mathrm{ND}^{* *}$ & 0,13 & 1,63 & 0,55 & 4,15 \\
\hline 19,5 & 27,1 & $1,7 \times 10^{4}$ & $-0,1$ & 0,42 & 1 & 1,14 & 0,35 & 1,49 & 1,77 & 0,78 & 3,33 \\
\hline 18,9 & 28,3 & $1,2 \times 10^{4}$ & $-0,22$ & 0,66 & 1 & 2,55 & 1,00 & 3,55 & 1,16 & 0,53 & 2,90 \\
\hline 17,8 & 29,6 & $1,3 \times 10^{4}$ & $-0,44$ & 0,92 & 1 & 1,82 & 0,41 & 2,23 & 1,53 & 0,29 & 3,34 \\
\hline 19,3 & 28,5 & $4,0 \times 10^{4}$ & $-0,14$ & 0,7 & 1 & 0,91 & 0,19 & 1,1 & 1,19 & 0,57 & 3,10 \\
\hline 17,6 & 29,3 & $6,5 \times 10^{4}$ & $-0,48$ & 0,86 & 1 & 1,61 & 0,21 & 1,82 & 1,33 & 0,25 & 2,89 \\
\hline 22,6 & 28,4 & $8,5 \times 10^{4}$ & 0,52 & 0,68 & 1 & 1,98 & 0,55 & 2,53 & 1,06 & 0,72 & 2,46 \\
\hline 20,5 & 28,0 & $9,0 \times 10^{4}$ & 0,1 & 0,6 & 1 & 0,87 & ND & 0,87 & 1,41 & 0,73 & 3,26 \\
\hline 19,5 & 30,0 & $1,9 \times 10^{4}$ & $-0,1$ & 1 & 1 & 0,72 & ND & 0,72 & 1,56 & 0,61 & 4,14 \\
\hline 20,0 & 30,0 & $3,2 \times 10^{4}$ & 0 & 1 & 1 & 0,07 & ND & 0,07 & 1,46 & 0,67 & 4,06 \\
\hline 20,0 & 25,0 & $1,9 \times 10^{4}$ & 0 & 0 & 1 & 0,52 & 0,05 & 0,57 & 4,55 & 1,50 & 6,05 \\
\hline 20,0 & 25,0 & $8,0 \times 10^{4}$ & 0 & 0 & 1 & 0,19 & 0,09 & 0,28 & 4,55 & 1,50 & 6,05 \\
\hline 19,0 & 25,0 & $2,1 \times 10^{4}$ & $-0,2$ & 0 & 1 & 0,55 & ND & 0,55 & 3,88 & 1,30 & 5,12 \\
\hline 18,0 & 30,0 & $1,6 \times 10^{4}$ & $-0,4$ & 1 & 1 & 0,15 & ND & 0,15 & 1,83 & 0,34 & 3,94 \\
\hline 17,0 & 30,0 & $2,4 \times 10^{4}$ & $-0,6$ & 1 & 1 & 1,95 & 1,09 & 3,04 & 2,00 & 0,11 & 3,45 \\
\hline 16,5 & 25,0 & $1,6 \times 10^{4}$ & $-0,7$ & 0 & 1 & 0,2 & ND & 0,2 & 1,14 & 0,60 & 1,54 \\
\hline 18,0 & 30,0 & $1,4 \times 10^{4}$ & $-0,4$ & 1 & 1 & 0,19 & ND & 0,19 & 1,83 & 0,34 & 3,94 \\
\hline
\end{tabular}

* $\mathrm{U}=$ umidade; $\mathrm{T}=$ temperatura; $\mathrm{I}=$ Fusarium spp. (considerando que o inóculo de F. verticillioides 103F aplicado no milho tratado foi de $\left.10^{4} \mathrm{UFC} / \mathrm{g}\right) .{ }^{* *} \mathrm{ND}=$ não detectado $(<100 \mathrm{UFC} / \mathrm{g})$.

Outrossim, estes níveis de fumonisinas têm sido detectados em casos reais de intoxicação animal na região, assim como em contaminação natural de milho. No primeiro trabalho publicado sobre intoxicação por fumonisinas no Brasil, os níveis de fumonisinas variaram de $0,2-38,5 \mu \mathrm{g} / \mathrm{g} \mathrm{FB}_{1}$ e $0,1-12,0$ $\mu \mathrm{g} / \mathrm{g} \mathrm{FB}$ (SYDENHAM et al., 1992), assim como de 2,89 a $14,54 \mu \mathrm{g} / \mathrm{g} \mathrm{FB}_{\text {total }}$ no monitoramento das safras 1991-1997 do Estado do Paraná (ONO et al., 2004). Por outro lado, no Estado de São Paulo, Camargos et al. (2000) detectaram níveis da toxina $\left(\mathrm{FB}_{\text {total }}\right.$ ) variando de 1,63 a $25,69 \mu \mathrm{g} / \mathrm{g}$ na safra $97 /$ 98. Abbas et al. (2006), analisando a contaminação de fumonisinas em híbridos de milho no Arkansas, detectaram níveis de 8,0 a 83,6 $\mu \mathrm{g} / \mathrm{g}$ na safra de 2001 . Procedendo à analogia entre estes dados de contaminação natural relatados com os nossos dados experimentais (Tabela 4), pode-se inferir que as condições que mantêm o metabolismo microbiano em atividade devem ser cessadas, de preferência nas fases de pré e pós-colheita.

Em relação às duas toxinas isoladamente, o somatório de $\mathrm{FB}_{1}$ e $\mathrm{FB}_{2}$, i.e. $\mathrm{FB}_{\text {total }}$, preditas pelos respectivos modelos foi, no contexto geral, inferior ao valor de $\mathrm{FB}_{\text {total }}$ obtido aplicando-se o modelo para este somatório (Tabela 4). Provavelmente isto decorreu devido aos baixos coeficientes de correlação obtidos para os modelos de $\mathrm{FB}_{1}$ e $\mathrm{FB}_{\text {total }}(61,8$ e $67,9 \%$, respectivamente, Tabela 3 ), demonstrando a necessidade de cautela na utilização destas equações de modelagem. 
Os níveis de $\mathrm{FB}_{1}$ e $\mathrm{FB}_{2}$ tanto dos dados reais, que variaram de $0,07-2,55 \mu \mathrm{g} / \mathrm{g}\left(\mathrm{FB}_{1}\right)$ e não detectado $-1,09 \mu \mathrm{g} / \mathrm{g}\left(\mathrm{FB}_{2}\right)$, quanto dos preditos pelos modelos, variação de 1,06- 4,55 $\mu \mathrm{g} / \mathrm{g}\left(\mathrm{FB}_{1}\right)$ e 0,11 $1,50 \mu \mathrm{g} / \mathrm{g}\left(\mathrm{FB}_{2}\right)$, foram inferiores ao encontrado no interior de São Paulo, cujos níveis médios foram de $5,61 \mu \mathrm{g} / \mathrm{g}$ para $\mathrm{FB}_{1}$ e $1,86 \mu \mathrm{g} / \mathrm{g}$ para $\mathrm{FB}_{2}$ (CAMARGOS et al., 2000).

Tendo em vista que a temperatura ótima determinada para a produção de fumonisinas no ensaio experimental inoculado com $F$. verticillioides $103 \mathrm{~F}$ em milho termicamente tratado situou-se a $20^{\circ}$ $\mathrm{C}$ e que, em valores superiores observou-se uma drástica redução na concentração da toxina (Figura 1); as elevadas temperaturas na moega durante a safra de verão (janeiro/abril, Projeto FINEP) - faixa de 25 a $30^{\circ} \mathrm{C}$, simulada na Tabela 4 - enfocaria condição externa não ideal para desencadear a biossíntese de fumonisina.

Considerando a presença de dois grandes grupos de fungos toxigênicos (Aspergillus spp. e Fusarium spp.) numa região subtropical com alta produtividade de milho, aliado a dados obtidos, o procedimento recomendado para a pré-estocagem de milho seria a secagem imediata a teores de umidade inferior a $15 \%$, mesmo mantendo temperatura de $20^{\circ} \mathrm{C}$ (Figura 1). Dados estes que confirmam o valor máximo permitido pela Legislação Federal de 14\% de umidade para conservação de sementes de milho (BRASIL, 1989).

Cromatogramas $F B_{1}$ e $F B_{2}$ em milho sob aspecto dinâmico de interação microbiana

A Figura 3 apresenta o perfil cromatográfico de substrato milho antes de iniciar o ensaio com inóculo de F. verticillioides $103 \mathrm{~F}\left(\mathrm{t}_{0}\right)$, tanto pré (Figura 3a) quanto pós (Figura $3 b$ ) tratamento térmico, referente à análise de fumonisinas por CLAE. Denota-se que o substrato original já continha fumonisinas, sendo que o tratamento térmico utilizado não causou redução relativa no teor, considerando $4,69 \mu \mathrm{g} / \mathrm{g}$ de $\mathrm{FB}_{\text {total }}$ no substrato original, em relação a 4,66 $\mu \mathrm{g} / \mathrm{g}$ de $\mathrm{FB}_{\text {total }}$ no substrato tratado termicamente, com picos nítidos de $\mathrm{FB}_{1}(6,7-6,9 \mathrm{~min})$ e FB 2 (12,1-12,3 min). Os picos cromatográficos adicionais provavelmente decorreram da presença de compostos de caráter catiônico, eluídos por solvente ácido, além de interferentes fluorescentes, oriundos de derivatização com orto-ftaldialdeído - OPA.

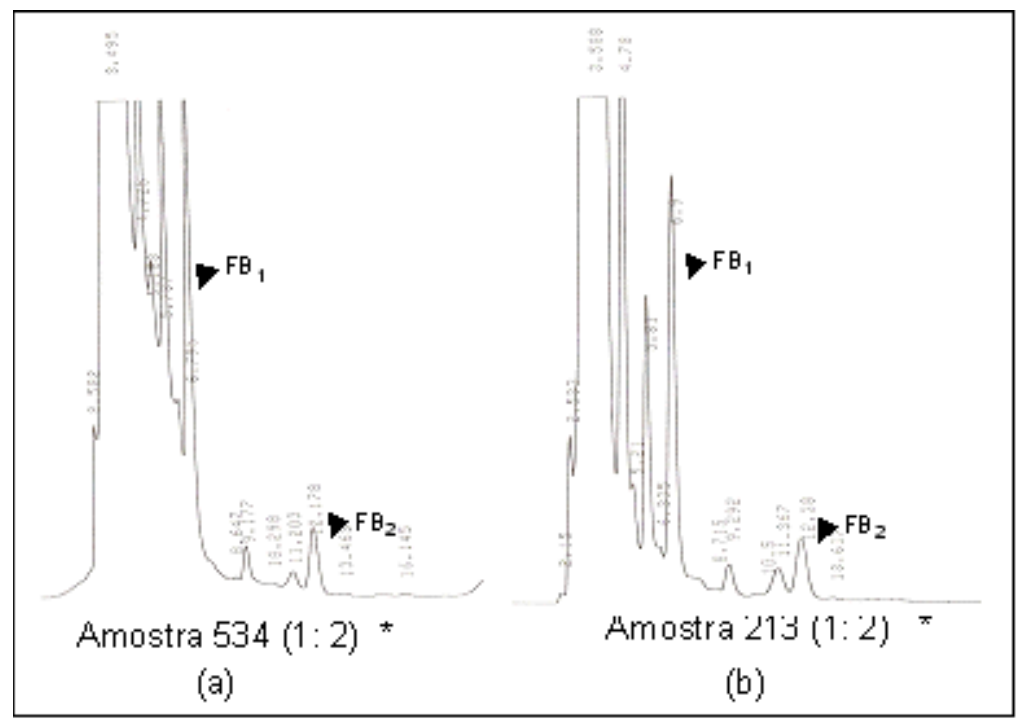

* codificação da amostra seguida da correspondente diluição.

Figura 3. Cromatogramas de $\mathrm{FB}_{1}$ e $\mathrm{FB}_{2}$ em milho no tempo zero $\left(\mathrm{t}_{0}\right)$ : (a) submetido ao tratamento térmico; (b) não submetido ao tratamento térmico. 


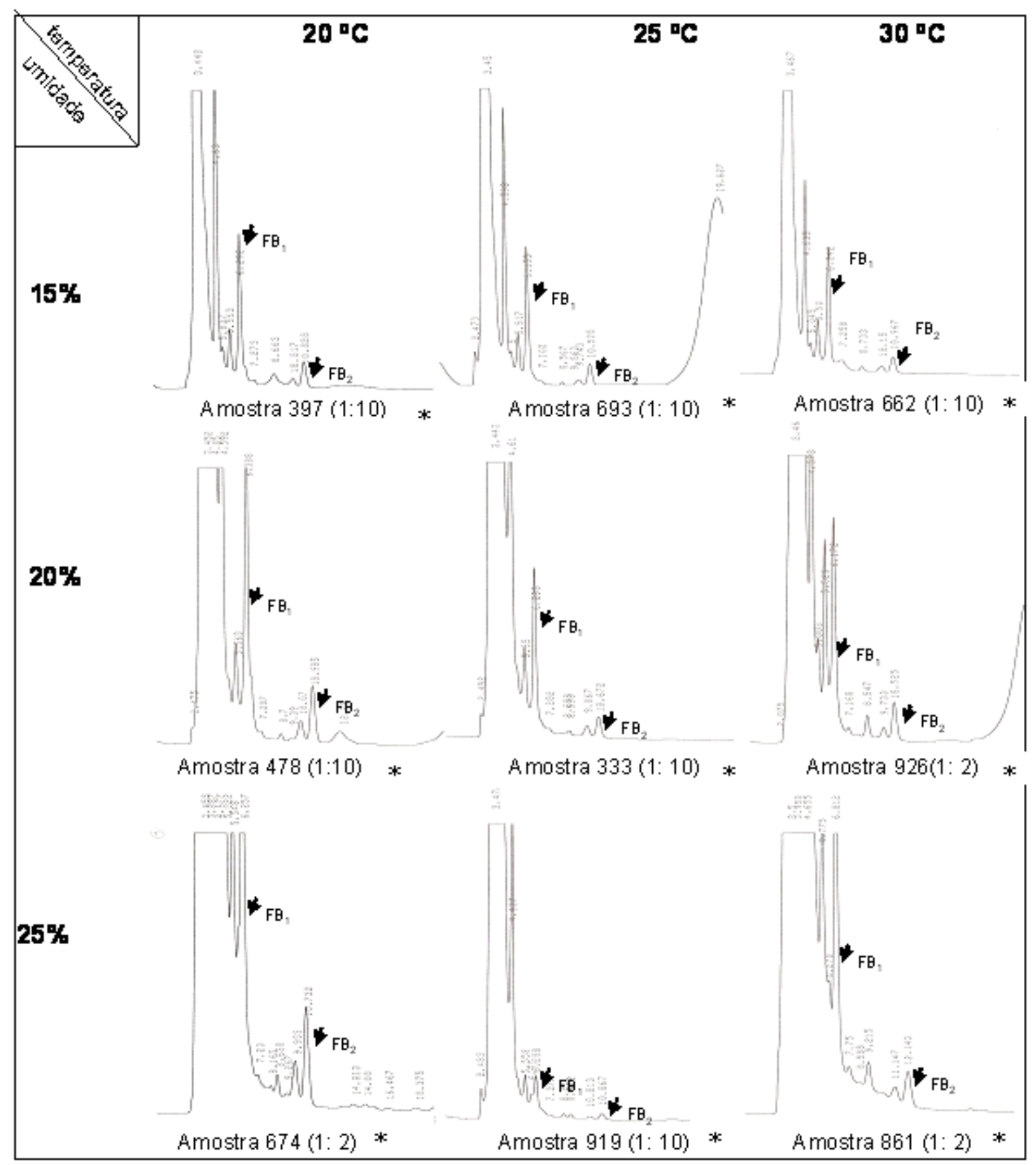

* codificação da amostra seguida da correspondente diluição.

Figura 4. Cromatogramas de $\mathrm{FB}_{1}$ e $\mathrm{FB}_{2}$ no substrato milho com tratamento térmico sem F. verticillioides $\left(\mathrm{t}_{20}\right)$. 


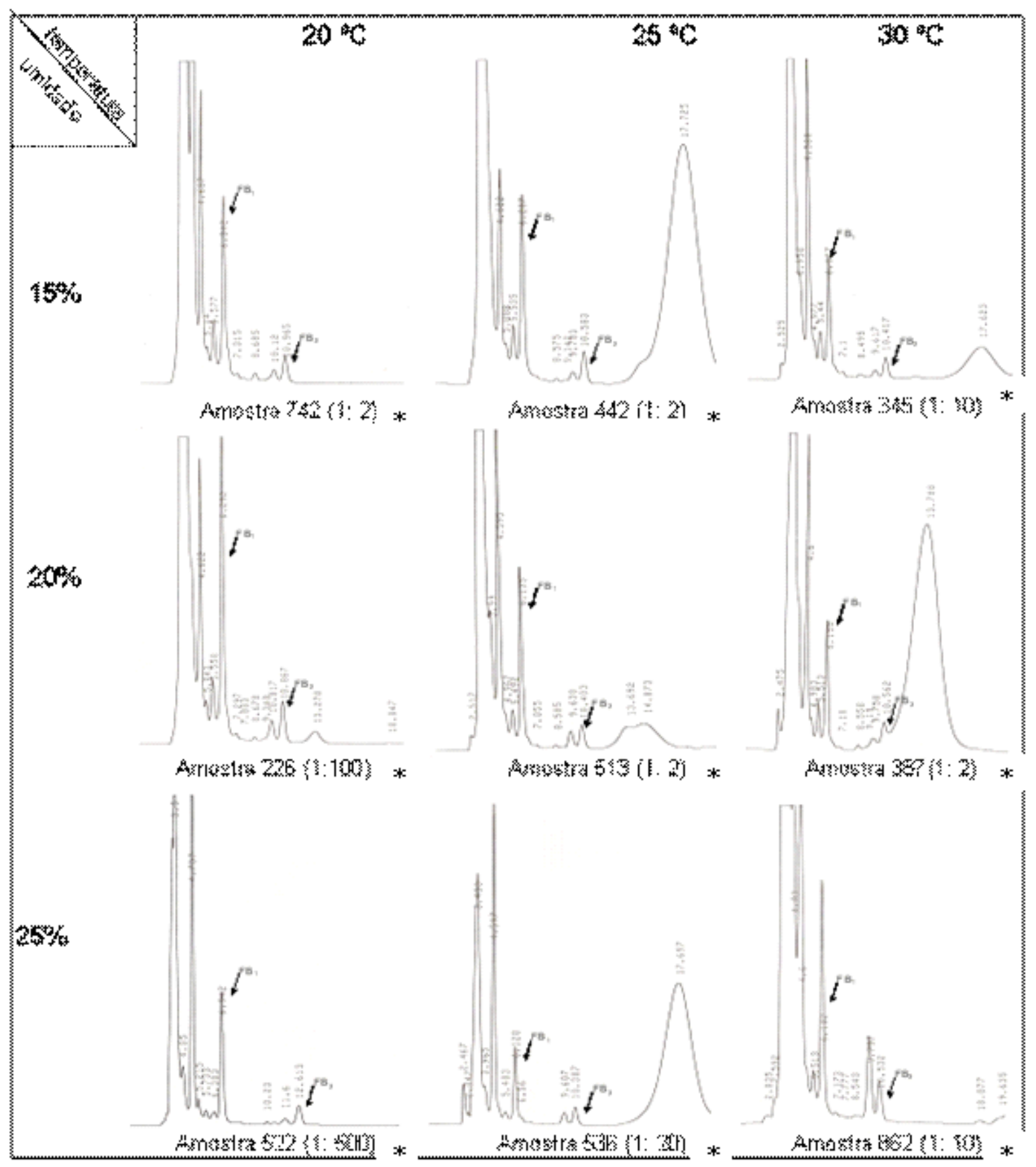

* codificação da amostra seguida da correspondente diluição.

Figura 5. Cromatogramas de $\mathrm{FB}_{1}$ e $\mathrm{FB}_{2}$ no substrato milho com tratamento térmico e contendo F. verticillioides ( $\mathrm{t}_{20}$ ). 
As figuras 5 e 6 apresentam os cromatogramas, respectivamente do extrato de milho submetido e não ao tratamento térmico, ambos inoculados com $F$. verticillioides 103F. A Figura 4 apresenta a mesma análise cromatográfica em extrato resultante de milho submetido ao tratamento térmico, mas sem o inóculo de F. verticillioides 103F. Estes perfis cromatográficos corresponderam à análise de extrato resultante de substrato milho no decorrer de 20 dias de incubação a $20-30^{\circ}$ C e $15-25 \%$ de umidade, conforme planejamento apresentado. Os cromatogramas foram obtidos procedendo à análise de extrato pós-coluna de limpeza diluído a 1:2, 1:10, 1:20, 1:50, 1:100 e 1:500, para obter pico com área que permita melhor análise quantitativa de fumonisinas, i.e., concentrações dentro do intervalo da curva padrão.

Em suma, considerando que o tempo de retenção aproximado de $\mathrm{FB}_{1}$ seja de 6 min e $\mathrm{FB}_{2}$ de 10-12 min, os cromatogramas obtidos indicaram a produção desta micotoxina em toda faixa de umidade e temperatura testada (figuras 4, 5 e 6). Todavia, uma observação interessante é sobre a diversidade nos perfis de picos cromatográficos apresentados sob diferentes condições de cultivo, resultantes de diferença na condição de incubação (temperatura e umidade), assim como sob aplicação ou não de tratamento térmico no substrato (figuras 3 a 6).

A diversidade de picos com tempos de retenção diferentes das fumonisinas, principalmente referente aos com tempos de retenção em 13-18 min, sugeriu presença de outros compostos oriundos de intensa atividade metabólica principalmente de $F$. verticillioides 103F, uma vez que, conforme demonstrado na Figura 4, estes picos não foram detectados no substrato não inoculado com esporos do fungo (inóculo $=-1$ ). Comparando as figuras 5 e 6, ambas inoculadas com $F$. verticillioides $103 \mathrm{~F}$, submetida e não ao tratamento térmico, respectivamente, o crescimento de outros gêneros fúngicos tendeu reduzir a produção de metabólitos correspondentes a estes picos, assim como de fumonisinas.
Todavia, o mesmo pico de interferente não foi observado no ensaio conduzido no substrato inoculado com $F$. verticillioides $103 \mathrm{~F}$ com $25 \%$ de umidade a $20^{\circ} \mathrm{C}$, onde ocorreu maior produção de fumonisinas (Figura 1). Portanto, estes metabólitos poderiam estar relacionados com a biossíntese de $\mathrm{FB}_{1}$ e $\mathrm{FB}_{2}$, porém numa relação inversa; ou ainda pertencer à categoria de um dos 28 análogos de fumonisina atualmente caracterizados (MUSSER; PLATTNER, 1997; RHEEDER; MARASAS; VISMER, 2002), porém com menor polaridade do que $\mathrm{FB}$, a exemplo daqueles sem o grupamento TCA (ácido tricarboxílico) na estrutura molecular, citandose a $\mathrm{AP}_{1}$.

Sendo assim, a $20^{\circ} \mathrm{C}$ e $25 \%$ de umidade a via biossintética não acumulou estes metabólitos adicionais, o que proporcionou menor concentração de interferentes na corrida cromatográfica. Desta maneira, sob esta condição, maior foi a concentração das duas fumonisinas quantificadas $\left(\mathrm{FB}_{1}\right.$ e $\left.\mathrm{FB}_{2}\right)$ e, conseqüentemente, seria a condição ideal para o cultivo destinado à obtenção de fumonisina purificada.

Salienta-se que estes metabólitos correspondentes aos picos com tempo de retenção em 13-18 min também não foram observados no substrato inicial, embora estivesse contaminado naturalmente ( $\mathrm{t}_{0}$; Figura 3). O fato indicaria metabólitos de F. verticillioides produzidos ao longo de 20 dias de incubação.

Comparando os cromatogramas apresentados nas figuras 5 e 6, em geral observa-se maior número de picos interferentes no substrato milho sem tratamento térmico (Figura 6), indicando que sejam provavelmente oriundos de metabolismo da micobiota natural de milho. Estes perfis evidenciaram a vantagem de milho esterilizado para a produção de fumonisinas, pela maior concentração obtida (diluição 1:500, cultivo a $20^{\circ} \mathrm{C}$ e $25 \%$ umidade), aliada a menor concentração de interferentes, conforme cromatograma apresentado na Figura 5. 


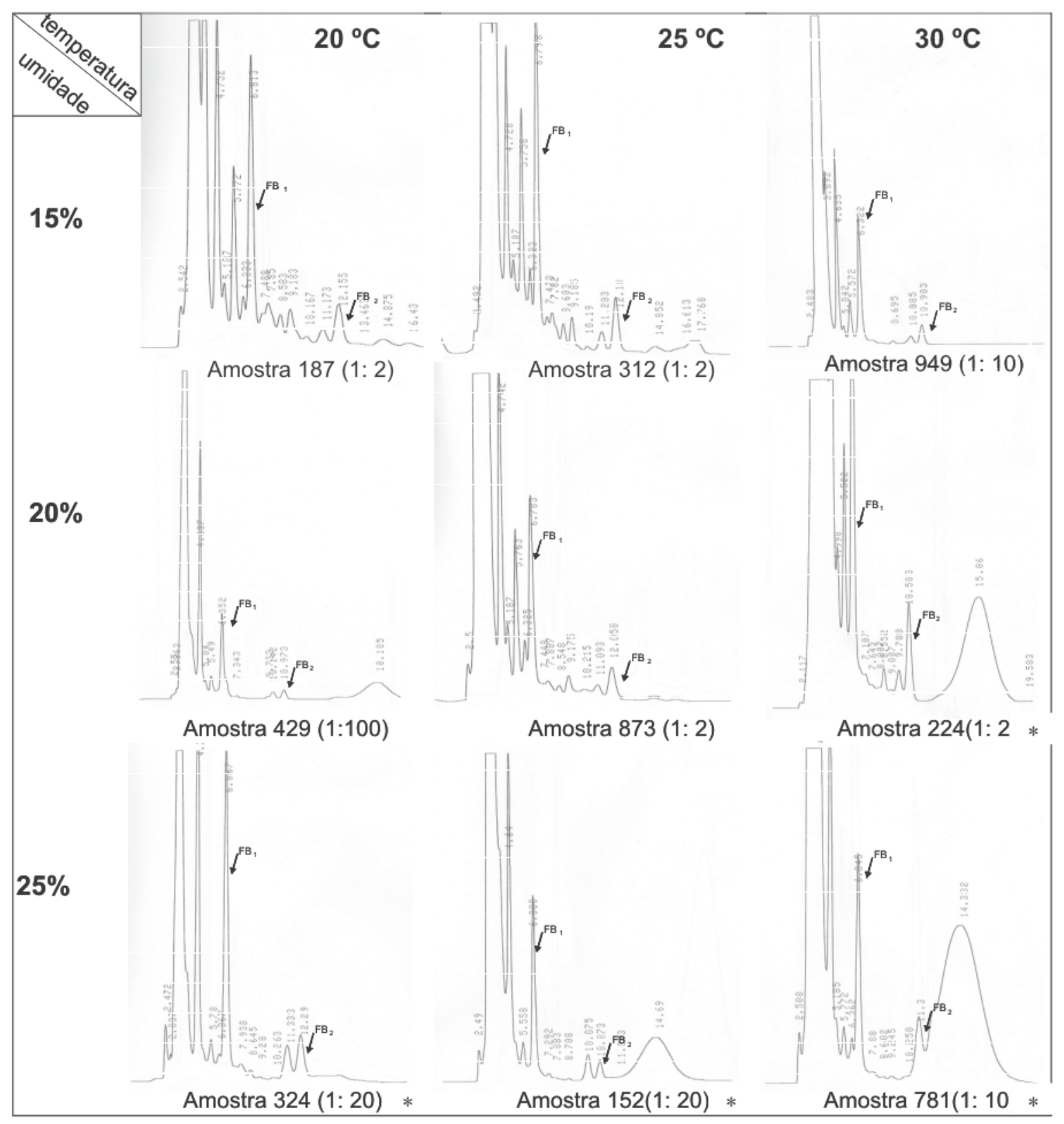

* codificação da amostra seguida da correspondente diluição

Figura 6. Cromatogramas de $\mathrm{FB}_{1}$ e $\mathrm{FB}_{2}$ no substrato milho sem tratamento térmico e com F. verticillioides $\left(\mathrm{t}_{20}\right)$. 


\section{Conclusão}

Os modelos desenvolvidos tratam-se de primeira etapa visando à predição do perigo de fumonisina em milho, visto que se adequaram aos índices estatísticos e matemáticos e de validação gráfica, dentro dos limites utilizados no estudo.

As informações obtidas destinam-se a tomada de decisão perante colheita, plantio ou armazenamento de milho, minimizando a deterioração, perda de qualidade e produção de fumonisina. É importante salientar, que outros parâmetros, a exemplo de condições de estocagem, oscilações de temperatura, presença de competidores, híbrido de milho, práticas agronômicas, agentes antifúngicos, também influenciariam nas respostas em nível de campo, inclusive no armazenamento.

\section{Agradecimentos}

Os autores agradecem ao Conselho Nacional de Pesquisa e Desenvolvimento Científico e Tecnológico (CNPq) pelas bolsas concedias aos pesquisadores deste estudo, FINEP, Fundação Araucária, Fundo Paraná-SETI e Associação Desenvolvimento Tecnológico de Londrina- ADETEC, pelo apoio financeiro. Aos pesquisadores Marcelo da Silva, Elaine Cunha Moreno, Dra. Maria Victória E. Grossmann e Plínio P.M. Uchoa Jr.

\section{Referências}

ABBAS, H. K.; CARTWRIGHT, R. D.; XIE, W.; SHIER, T. Aflatoxin and fumonisin contamination of corn (maize, Zea mays) hybrids in Arkansas. Crop Protection, Guildford, v. 25, n. 1, p. 1-9, 2006.

BRASIL. Ministério da Agricultura e Reforma Agrária. Comissão Nacional de Sementes e Mudas. Brasília: Ministério da Agricultura e Reforma Agrária, 1989.

BULLERMAN, L. B. Occurrence of Fusarium and fumonisins on food grains and in foods. In: JACKSON, L. S.; DEVRIES, J. W.; BULLERMAN, L. B. (Ed.) Fumonisins in food. New York: Plenum Press, 1996. p. 27-33.

CAMARGOS, S. M.; SOARES, L. M. V.; SAWAZAKI, E.;
BOLONHEZI, D.; CASTRO, J. L.; BORTOLLETO, N. Fumonisins in corn cultivars in the state of São Paulo. Brazilian Journal of Microbiology, São Paulo, v. 31, n. 3, p. 226-229, 2000.

DILKIN, P.; MALLMANN, C. A.; ALMEIDA, C. A. A.; STEFANON, E. B.; FONTANA, F. Z.; MILBRADT, E. L. Production of fumonisins by strains of Fusarium moniliforme according to temperature, moisture and growth period. Brazilian Journal of Microbiology, São Paulo, v. 33, p. 111-118, 2002.

FINANCIADORA DE PRODUTOS E PROJETOS-FINEP; FUNDO NACIONAL DE DESENVOLVIMENTO CIENTÍFICO TECNOLÓGICO - FNDCT. Arranjo agroindustrial da região de londrina: detecção de pontos críticos, monitoramento e controle dos fatores que afetam a qualidade do milho e derivados. Londrina: UEL/ ADETEC/Cooperativa Agropecuária de Produção Integrada do Paraná/Caramuru Alimentos/Kowalski Alimentos, 2004. Convênio ref. 0601/02, FNDCT-MCT.

HINOJO, M. J.; MEDINA, A.; VALLE-ALGARRA, F. M.; GIMENO-ADELANTADO, J. V.; JIMÉNEZ, M.; MATEO, R. Fumonisin production in rice cultures of Fusarium verticillioides under different incubation conditions using an optimized analytical method. Food Microbiology, London, v. 23, n. 2, p. 119-127, 2006.

HIROOKA, E. Y.; YAMAGUCHI, M. M.; AOYAMA, S. The natural occurrence of fumonisin in Brazilian corn kernels. Food Additives and Contaminants, London, v. 13, n. 2, p. 173-183, 1996.

WORLD HEALTH ORGANIZATION. INTERNATIONAL AGENCY FOR RESEARCH ON CANCER - IARC. IARC monographs on the evaluantion of carcinogenic risks to human. Lyon: IARC, 2002. p. 301. (Some traditional herbal medicines, some mycotoxins, naphthalene and styrene, $\mathrm{v}$. 82)

INSTITUTO BRASILEIRO DE GEOGRAFIA E ESTATÍSTICA - IBGE. Levantamento sistemático da produção agrícola. Disponível em: <http:// www.ibge.gov.br/ibge/estatistica/indicadores/ agropecuaria/lspa>. Acesso em: 12 fev. 2007.

KADOZAWA, P.; FIGUEIRA, E. L. Z.; MARSARO JÚNIOR,A. L.; GERAGE, A. C.; LAZZARI, S. M. N.; ONO, E. Y. S.; MIZUBUTI, I. Y.; HIROOKA, E. Y. Atividade inibidora de amilase e protease de milho contra Fusarium verticillioides durante a germinação. Semina: Ciências Agrárias, Londrina, v. 27, n. 2, p. 231-242, abr.jun. 2006.

LAZZARI, F. A.; LAZARRI, S. M. N. Microrganismos, micotoxinas e protetores antifúngicos. In: SCUSSEL, V. M. (Ed.). Atualidades em micotoxinas e armazenagem qualitativa de grãos. Florianópolis: do autor, 2000. p. 
MALLMANN, C.; SANTURIO, J. M.; DILKIN, P. Incidência de fumonisina $B_{1}$ em milho e rações no Brasil. In: CONGRESSO LATINO AMERICANO DE MiCOTOXICOLOGIA, 7., 1997, Maracay. Anais... Maracay: Sociedad LatinoAmericana de Micotoxicologia, 1997.p.73.

MALLMANN, C. A. Micotoxinas. In: CONGRESSO URUGUAYO DE PRODUCCION PORCINA, 1., 1998. Anais... Punta Del Leste: Ed., 1998. p. 119-125.

MUNKVOLD, G. P.; DESJARDINS, A. E. Fumonisins in maize: can we reduce their occurrence? Plant Disease, Saint Paul, v. 81, n. 6, p. 556-565, jun. 1997.

MUSSER, S. M.; PLATTNER, R. D. Fumonisin composition in culture of Fusarium moniliforme, Fusarium proliferatum and Fusarium nygamae. Journal Agricultural and Food Chemistry, Easton, v. 45, n. 4, p. 1169-1173, 1997.

ONO, E. Y. S.; SUGIURA, Y.; HOMECHIN, M.; KAMOGAE, M.; VIZZONI, E.; UENO, Y.; HIROOKA, E. Y. Effect of climatic conditions on natural mycoflora and fumonisins in freshly harvested corn of the State of Paraná, Brazil. Mycopathologia, Den Haag, v. 147, n. 3, p. 139-148, 1999.

ONO, E. Y. S.; FUNGARO, M. H. P.; SOFIA, S. H.; FIGUEIRA, E. L. Z.; GERAGE, A. C.; ICHINOE, M.; SUGIURA, Y.; UENO, Y.; HIROOKA, E. Y. Trends of fumonisin contamination and animal intoxication through monitoring 1991 to 1997 corn crop in the State of Paraná, Brazil. Mycopathologia, Den Haag, v. 158, n. 4, p. 451455, 2004.

ORSI, R. B.; CORRÊA, B.; POZZI, C. R. Mycoflora and occurrence of fumonisins in freshly harvested and stored hybrid maize. Journal Stored Products Research, Oxford, v. 36, n. 1, p. 75-87, 2000.

RHEEDER, J. P.; MARASAS, W. F. O.; VISMER, H. F. Production of fumonisin analogs by Fusarium species. Applied and Environmental Microbiology, Washington, v. 68, n. 5, p. 2101-2105, 2002.
RODRIGUEZ-AMAYA, D. B. Occurrence of micotoxins and micotoxin-producing fungi in Latin America. In: DE KOE, W. J.; SAMSON, R. A.; VAN EGMOND, H. P.; GILBERT, J.; SABINO, M. (Ed.). Mycotoxins and phycotoxins in perspective at the turn of the millennium. Wageningen: Ponsen and Looyen, 2000. p. 309-320.

SCOTT, P. M. Fumonisins. International Journal Food Microbiology, Amsterdam, v. 18, n. 4, p. 257-270, 1993.

SCUDAMORE, K. A.; PATEL, S. Survey for aflatoxins, ochratoxin A, zearalenone and fumonisins in maize imported into the United Kingdom. Food Additives and Contaminants, London, v. 17, n. 5, p. 407-416, 2000.

SHEPHARD, G. S.; SYDENHAM, E. W.; THIEL, P. G.; GELDERBLOM, W. C. A. Quantitative determination of fumonisins $B_{1}$ and $B_{2}$ by high-performance liquid chromatography with fluorescence detection. Journal of Liquid Chromatography, Granada, v. 13, n. 10, p. 20772087, 1990 .

SYDENHAM, E. W.; MARASAS, W. F. O.; SHEPHARD, G. S.; THIEL, P. G.; HIROOKA, E. Y. Fumonisin concentration in Brazilian feeds associated with field outbreaks of animal mycotoxicosis. Journal of Agricultural and Food Chemistry, Easton, v. 40, n. 6, p. 994-997, 1992.

UENO, Y.; AOYAMA, S.; SUGIURA, Y.; WANG, D. S.; HIROOKA, E. Y.; HARA, S.; KARKI, T.; CHEN, G.; YU, S. $\mathrm{H}$. A limited survey of fumonisin in corn and corn-based products in Asian countries. Mycotoxin Research, Alemanha, v. 9, n. 1, p. 27-34, 1993.

YAMAGUCHI, M. M.; HIROOKA, E. Y.; SHIBATA, T. M. M. Fumonisinas em milho no Estado do Paraná. In: ENCONTRO NACIONAL DE MICOTOXINAS, 7., 1992, São Paulo. Anais... São Paulo: Instituto Adolfo Lutz, 1992. p. 27. 
